\title{
Ophthalmology
}

\section{Analyzing Trace Elements in the Structures of Glaucomatous Eyes}

\author{
Elena Iomdina, $\mathrm{PhD}, \mathrm{ScD}^{1 *}$; Lusine Arutyunyan, $\mathrm{PhD}, \mathrm{ScD}^{2}$; Elena Khorosheva ${ }^{3}$ \\ ${ }^{1}$ Moscow Helmholtz Research Institute of Eye Diseases \\ ${ }^{2}$ Eye Center "East Sight Recovery" \\ ${ }^{3}$ V.M. Gorbatov Federal Research Center for Food Systems of RAS \\ Moscow, the Russian Federation
}

\begin{abstract}
Trace elements (TE) were analyzed in sclera biopsy specimens, samples of anterior chamber aqueous humor, and tear fluid of 12 patients aged between 53 and 79 years with various stages of primary open-angle glaucoma (POAG), using an atomic absorption spectrometer AS-3, inductively coupled plasma-mass spectrometer ELAN 6100-ICP-MS (Perkin-Elmer), and a Thermo Scientific plasma spectrometer iCAP-7000 (USA). Detected irregularities in the content of some TE (magnesium, iron, zinc, etc.) in anterior chamber aqueous humor of POAG patients may be a serious pathogenetic factor that violates the viscosity, and hence, the hydrodynamics, of intraocular fluid. An imbalance of TE in the tissues and media of glaucomatous eyes can contribute to the development of glaucomatous damage. (International Journal of Biomedicine. 2019;9(1):23-25.)
\end{abstract}

Key Words: sclera $\bullet$ anterior chamber $\bullet$ aqueous humor $\bullet$ trace elements $\bullet$ glaucoma

\section{Abbreviations}

ACAH, anterior chamber aqueous humor; POAG, primary open-angle glaucoma; TE, trace elements.

\section{Introduction}

Recent studies have shown that biomechanical disorders of the corneoscleral shell are an important factor in the pathogenesis of POAG. ${ }^{(1-6)}$ It has been found that with POAG, excessive intramolecular and intermolecular cross-links are formed in the collagen structures of the sclera, contributing to an increase in its rigidity. ${ }^{(4,7)}$ At the same time, it is known that some TE (zinc, copper, aluminum, silicon, etc.) involved in collagen biosynthesis and fibril formation, as well as in the antioxidant protection mechanism, play a key role in the posttranslational modifications of collagen and in the formation of cross-links. ${ }^{(8-1)}$ Changes in the content of these TE may contribute to the development of ophthalmic pathology. In particular, it was shown that weakened support function of the sclera, a key factor in the progression of myopia, is

*Corresponding author: Prof. Elena N. Iomdina, PhD, ScD. Moscow Helmholtz Research Institute of Eye Diseases. Moscow, Russia.E-mail: iomdina@mail.ru largely associated with a certain imbalance of TE, leading to a decrease in the number of cross-links stabilizing the sclera. ${ }^{(3)}$

The significance of TE, a large group of chemicals whose content in the body does not exceed $10^{-9}-10^{-12}$ mass percent, is extremely high and diverse in the life of cells and in maintaining the internal environment of the body, and is not inferior to the role of vitamins. ${ }^{(8,9,12)}$ An essential feature of essential TE in their optimal doses is that each of them activates a more or less extensive group of enzymes (although the activation mechanisms may be different). In this regard, a considerable amount of attention has been paid to the study of the TE participation in the physiological and pathological processes in the eye. ${ }^{(10,12,13)}$ However, studies aimed at the role of TE in the pathogenesis of glaucoma are practically absent. Individual studies focusing on trace element analysis of ACAH in patients with glaucoma indicate the promise of further development in this scientific direction. ${ }^{(13-15)}$

The aim of our work was to study the content of TE in the tissues and media of the glaucomatous eye involved in the metabolism of connective tissue and in the functioning of the antioxidant defense system. 


\section{Materials and Methods}

Scleral biopsy samples, ACAH samples (obtained during antiglaucomatous interventions) and tear fluid samples were collected from 12 patients ( 8 women and 4 men) aged between 53 and 79 years with different stages of POAG (the initial stage [I-II] in 6 patients and the advanced stage [III] in 6 patients). All samples were subjected to trace element analysis. Samples of ACAH, obtained during the extraction of immature senile cataract, and tear fluid samples, obtained from 18 patients ( 10 women and 8 men) aged between 54 and 70 years without ophthalmic pathology other than immature cataracts served as the control. Eight sclera samples were taken from the eyes of patients without glaucoma, which had to be removed due to severe eye injury.

For analysis, $100 \mu \mathrm{l}$ of ACAH sample were taken with a microdispenser and placed in a Teflon autoclave, to which $0.5 \mathrm{ml}$ of $70 \% \mathrm{HNO}_{3}$ and $0.1 \mathrm{ml}$ of $30 \% \mathrm{H}_{2} \mathrm{O}_{2}$ were added. Then, the autoclave was placed in a microwave sample preparation system similar to MD-2000 (CEM, USA) to attain a higher pressure and the boiling point temperature of $\mathrm{HNO}_{3}$. The samples were decomposed within 15 minutes in three heating-cooling cycles. After cooling for 10-15 min, the resulting solutions were diluted 5 times with doubledistilled and deionized water. Separately, a control solution was prepared with the content of $\mathrm{HNO}_{3}, \mathrm{H}_{2} \mathrm{O}_{2}$, and $\mathrm{H}_{2} \mathrm{O}$ (double-distilled and deionized) in proportions identical to the ones used in the studied samples. As an internal standard, indium was introduced into the solutions at a concentration of $25 \mu \mathrm{g} / \mathrm{L}$. Calibration solutions were prepared from standard VTRC solutions with the known content of TE in the range of $5-1000 \mu \mathrm{g} / \mathrm{L}$. Analysis of TE content ( $\mathrm{Zn}, \mathrm{Cu}, \mathrm{Fe}, \mathrm{Al}, \mathrm{Ba}$ $\mathrm{Cr}, \mathrm{Si}, \mathrm{Mg}, \mathrm{Mn}, \mathrm{Ti}$ ) was carried out using an AS-3 atomic absorption spectrometer and a mass spectrometer with an ion source in the form of inductively coupled plasma ELAN 6100-ICP-MS (Perkin-Elmer). The working power of the microwave generator was set at $1.3 \mathrm{~kW}$, the flow rate of the plasma gas (argon) at $14 \mathrm{~L} / \mathrm{min}$, and the flow rate of the carrier gas at $0.89 \mathrm{ml} / \mathrm{min}$.

Three exposures of each sample were conducted with the integration time of the signal set at 60 seconds. The results of the control analysis were automatically subtracted in the analysis. Samples of the sclera were degreased with ether, dried, weighed on an analytical balance and then placed in centrifuge tubes; $2 \mathrm{ml}$ of nitric acid were added to the tubes and heated in a sand bath for 20-25 minutes until a clear solution was obtained. The resulting solutions were brought to a volume of $10 \mathrm{ml}$ with double-distilled water. The analysis was performed by atomic emission spectral analysis using an iCAP-7000 plasma spectrometer (Thermo Science H, USA). As the excitation source, ${ }^{(16)}$ the inductively coupled plasma was used with a generator power of $1.5 \mathrm{~kW}$, a temperature of $8000{ }^{\circ} \mathrm{K}$, and a working flame height of $15 \mathrm{~mm}$. The units of the studied elements were $\mu \mathrm{g} / \mathrm{L}$ (ppb) and $\mathrm{mg} / \mathrm{kg}$.

Statistical analysis was performed using the statistical software «Statistica» (v6.0, StatSoft, USA). Values are presented as mean \pm standard deviation (SD). The MannWhitney U Test was used to compare the differences between the two independent groups. A probability value of $P<0.05$ was considered statistically significant.

This study was performed in accordance with the Declaration of Helsinki and was approved by Local Committee of Biomedical Ethics of the Moscow Helmholtz Research Institute of Eye Diseases. Written informed consent was obtained from all participants.

\section{Results}

The following results indicate significant changes in the level of TE in ACAH during the development of the glaucomatous process (Table 1).

Table 1.

The content of TE $(\mathrm{mg} / \mathrm{L})$ in $A C A H$ of patients with different stages of POAG

\begin{tabular}{|l|c|c|c|}
\hline \multirow{2}{*}{ Element } & \multicolumn{2}{|c|}{ Glaucoma stage } & \multirow{2}{*}{ Control group } \\
\cline { 2 - 3 } & I-II & III & \\
\hline $\mathrm{Al}$ & $0.035 \pm 0.017$ & $0.012 \pm 0.006^{*}$ & $0.0311 \pm 0.007$ \\
\hline $\mathrm{Ba}$ & $0.0067 \pm 0.0023$ & $0.0057 \pm 0.003^{*}$ & $0.0079 \pm 0.0028$ \\
\hline $\mathrm{Cu}$ & $0.0150 \pm 0.0011^{*}$ & $0.0090 \pm 0.006^{*}$ & $0.0210 \pm 0.009$ \\
\hline $\mathrm{Fe}$ & $0.146 \pm 0.051^{*}$ & $0.220 \pm 0.058^{*}$ & $0.053 \pm 0.014$ \\
\hline $\mathrm{Mg}$ & $5.9 \pm 0.51$ & $3.0 \pm 0.43^{*}$ & $6.70 \pm 0.94$ \\
\hline $\mathrm{Mn}$ & $0.0044 \pm 0.0006^{*}$ & $0.0009 \pm 0.00008^{*}$ & $0.0120 \pm 0.0035$ \\
\hline $\mathrm{Si}$ & $1.8 \pm 1.2$ & $0.34 \pm 0.21^{*}$ & $1.9 \pm 1.3$ \\
\hline $\mathrm{Ti}$ & $0.005 \pm 0.007$ & $0.006 \pm 0.009$ & $0.0058 \pm 0.0017$ \\
\hline $\mathrm{Zn}$ & $0.124 \pm 0.06$ & $0.090 \pm 0.04^{*}$ & $0.139 \pm 0.03$ \\
\hline $\mathrm{Cr}$ & $0.0045 \pm 0.001 *$ & $0.0073 \pm 0.002^{*}$ & $0.0284 \pm 0.006$ \\
\hline
\end{tabular}

$* P<0.05$ - differences between Control group and Glaucoma stage

As can be seen from the data presented in Table 1, as the glaucomatous process progressed in the anterior chamber, the level of $\mathrm{Fe}$ in ACAH increased and the content of $\mathrm{Zn}$, $\mathrm{Cu}, \mathrm{Mg}$, and $\mathrm{Cr}$ decreased. Primarily in the level of $\mathrm{Zn}, \mathrm{Mg}$, and $\mathrm{Fe}$, these differences indicated an increased viscosity of the intraocular fluid in glaucoma, since the nature of the imbalance was very similar to the deviations found in the trace element content of POAG patients' blood. ${ }^{(15,18)}$ According to $\mathrm{J} . \mathrm{Ge},{ }^{(18)}$ with POAG there is a disturbance in the rheological properties of blood (hyperviscosity syndrome) associated with an abnormal level of the listed TE, which contributes to the deterioration of the blood supply to the glaucomatous eye and a decrease in visual function. It should be noted that the decreased $\mathrm{Zn}$ level in ACAH in patients with glaucoma has also been detected by N. Akyol et al. ${ }^{(14)}$

The detected elevated content of Fe, also known to have a prooxidant effect, in ACAH of POAG patients correlates with a high level of iron-containing transferrin protein in the intraocular fluid of an exfoliative glaucomatous eye. ${ }^{(17)}$ This elevated content of $\mathrm{Fe}$ undoubtedly indicates the increase of peroxidation processes amongst weakening antioxidant protection in the media of glaucomatous eyes. In eyes with 
POAG, we also detected a decrease in intraocular fluid resistance to oxidative stress correlated to a decrease in the $\mathrm{Mg}$ level (Table 1), which is involved in suppressing peroxidation processes.

With POAG, the sclera, as well as the intraocular fluid, was characterized by an abnormal balance of the studied microelements (Table 2). First, there was a decrease in the copper content (from $1.2 \mathrm{mg} / \mathrm{kg}$ in the initial stage to $0.77 \mathrm{mg} / \mathrm{kg}$ in the advanced stage of POAG). A decrease in zinc level and an increase in Fe level were also detected. This observation was consistent with the dynamics of the microelement levels in ACAH. Notably, our study of the $\mathrm{Mg}$ level showed a significant decrease with the progression of glaucomatous lesions. The $\mathrm{Mg}$ concentration in eye sclera samples was $19.3 \pm 1.8 \mathrm{mg} / \mathrm{kg}$ in POAG stage I-II and $17.5 \pm 1.2$ $\mathrm{mg} / \mathrm{kg}$ in POAG stage III. This measurement was significantly lower than the $\mathrm{Mg}$ level in normal scleral tissue of the anterior region- $29.0 \pm 6.0 \mathrm{mg} / \mathrm{kg}(P<0.001)$.

Table 2.

The content of $T E(\mathrm{mg} / \mathrm{kg})$ in the scleral tissue of patients with POAG

\begin{tabular}{|l|c|c|c|}
\hline \multirow{2}{*}{ Element } & \multicolumn{2}{|c|}{ Glaucoma stage } & \multirow{2}{*}{ Control group } \\
\cline { 2 - 3 } & I - II & III & \\
\hline $\mathrm{Cu}$ & $1.2 \pm 0.13$ & $0.77 \pm 0.12^{*}$ & $1.38 \pm 0.11$ \\
\hline $\mathrm{Fe}$ & $48.03 \pm 3.2$ & $68.03 \pm 4.3^{*}$ & $42.03 \pm 4.0$ \\
\hline $\mathrm{Mg}$ & $19.3 \pm 1.8^{*}$ & $17.5 \pm 1.2^{*}$ & $29.0 \pm 6.0$ \\
\hline $\mathrm{Zn}$ & $68.0 \pm 3.9$ & $39.0 \pm 4.1^{*}$ & $69.0 \pm 4.2$ \\
\hline
\end{tabular}

$* P<0.05$ - differences between Control group and Glaucoma stage

According to the literature, the concentration of $\mathrm{Mg}$ in the tear fluid of healthy eyes is comparable with (or slightly lower than) its level in blood serum (i.e., for the older age group, it is $0.66-0.99 \mathrm{mmol} / \mathrm{L}){ }^{(10)}$ At the same time, the results of our research on the trace element analysis of tear fluid showed that the $\mathrm{Mg}$ level in this biological fluid of POAG patients was detected in trace amounts.

In conclusion, the trace element analysis of glaucomatous eyes and eye tissues revealed an imbalance in TE that contributes to the formation of excessive crosslinks in the collagen structures of the sclera. Specifically, we observed a deficiency in magnesium, an element that is necessary for regulating the metabolism of pathologically changed connective tissue structures of glaucomatous eyes. Detected irregularities in the content of some TE (magnesium, iron, zinc, etc.) in ACAH of POAG patients may be a serious pathogenetic factor that violates the viscosity, and hence, the hydrodynamics, of intraocular fluid.

\section{Competing Interests}

The authors declare that they have no competing interests.

\section{References}

1. Coudrillier B, Pijanka JK, Jefferys JL, Goel A, Quigley HA, Boote C, Nguyen TD. Glaucoma related changes in the mechanical properties and collagen micro-architecture of the human sclera. PLoS ONE. 2015;10(7):e0131396. doi: 10.1371/journal.pone.0131396.

2. Coudrillier B, Tian J, Alexander S, Myers KM, Quigley HA, Nguyen TD. Biomechanics of the human posterior sclera: age- and glaucoma-related changes measured using inflation testing. Invest Ophthalmol Vis Sci. 2012;53(4):1714-28. doi: 10.1167/iovs.11-8009.

3. Iomdina EN, Bauer SM, Kotliar KE. Eye Biomechanics: theoretical aspects and clinical applications. Moscow: Real Time; 2015. [In Russian].

4. Iomdina EN, Ignatieva NYu, Danilov NA, Arutiunian LL, Kiseleva OA, Nazarenko LA. [Biochemical, structural and biomechanical features of human scleral matrix in primary open-angle glaucoma]. Vestnik Oftal'mologii. 2011;6:10-14. [Article in Russian].

5. Quigley HA. The contribution of the sclera and lamina cribrosa to the pathogenesis of glaucoma: Diagnostic and treatment implications. Prog Brain Res. 2015;220:59-86. doi: 10.1016/bs.pbr.2015.04.003.

6. Sigal IA, Ethier CR. Biomechanics of the optic nerve head. Exp Eye Res. 2009; 88(4):799-807. doi: 10.1016/j.exer.2009.02.003.

7. Danilov NA, Ignatieva NYu, Iomdina EN, Arutyunyan LL, Grokhovskaya TE, Lunin VV. Sclera of the Glaucomatous eye: Physicochemical Analysis. Biophysics. 2011;56:490-495. 8. Avtsyn AP, Zhavoronkov AA, Rish MA, Strochkova LS. Microelementosis in humans: etiology, classification, organopathology. M.: Meditsina. [In Russian].

9. Colotti G, Ilari A, Boffi A, Morea V. Metals and metal derivatives in medicine. Mini Rev Med Chem. 2013;13(2):211-21. 10. Giordano R, Costantini S, Vernillo I, Rizzica M. Atomic absorption techniques for the microdetermination of multielements in whole tear film. Atomic Spectroscopy. 1983;4(4):157-159.

11. Last J, Armstrong L Reiser K. Biosynthesis of collagen cross-links. Int J Biochem. 1990;22(6):559-564.

12. Prasad AS. Clinical, biochemical and nutritional aspects of trace elements. New York; 1972.

13. Iomdina EN, Kiseleva OA, Arutyunyan LL, Arefyeva MV. [Trace Element Imbalance in the Pathogenesis of Primary Open-Angle Glaucoma]. Russian Ophthalmological Journal. 2012;5(1):104-108. [Article in Russian].

14. Akyol N, Deger O, Keha E, Kilic S. Aqueous humour and serum, zinc and copper concentrations of patients with glaucoma and cataract. Br J Ophthalmol. 1990;74(11):661-662. 15. Weale RA. A biography of the eye - development, growth, age. London: H.K. Lewis \& Co. LTD; 1982.

16. Vis RD, Prins M. Trace element analysis in biological specimens. Chem Br. 1986;22(9):851-853.

17. Koliakos GG, Konstas AG, Dimitrakoulias N, Triantos A, Kardasopoulos A, Dimitriadou A, Trakatellis AC. Possible role of transferrin in exfoliation syndrome. Acta Ophthalmol Scand. 1996;74(2):155-9.

18. Ge J. [The hemorheological features and other related factors in patients with primary open angle glaucoma (POAG)]. Zhonghua Yan Ke Za Zhi. 1992;28(5): 298-302. [Article in Chinese]. 